\title{
Variaciones europeas en la visión del otro: un estudio contrastivo sobre la otredad en Antonio de Berrío y Walter Ralegh
}

\author{
Juan Manuel Díaz Ayuga ${ }^{1}$
}

Resumen. La presente investigación parte de la certeza de que, dentro de la visión general, de carácter europeizante e imperialista, que el sujeto colonial europeo tiene de la alteridad americana, existen toda una serie de profundas diferencias políticas, económicas, culturales o religiosas en la visión con la que los exploradores pertenecientes a diversas naciones europeas construyeron al "otro" indígena. Es desde esta certeza que el análisis contrastivo de la otredad en las crónicas de Antonio de Berrío y Walter Ralegh, quienes entraron en contacto con las mismas poblaciones nativas del Orinoco y Guayana en un mismo periodo de tiempo (últimas décadas del s. XVI), se erige como un caso de estudio paradigmático que puede apuntar a nuevas investigaciones en torno a las variaciones intraeuropeas en la construcción de la alteridad.

Palabras clave: Crónicas de Indias; otredad; sujeto colonial; visión; Antonio de Berrío; Walter Ralegh.

[en] European variations in the vision of the other: a contrastive study about otherness in Antonio de Berrío and Walter Ralegh

\begin{abstract}
This research study results from the conviction that, within the broad Europeanising and imperialist vision from which the European colonial subject represents American otherness, there are a number of considerable political, economic, cultural or religious differences between the visions of those explorers coming from different European countries. From this conviction, a contrastive analysis of otherness in the chronicles of Antonio de Berrío and Walter Ralegh, who made contact with the same native societies in Orinoco and Guiana during the same period of time (last decades of the $16^{\text {th }}$ century), stands as a paradigmatic case study which may be the basis for new research works about intra-European constructions of otherness.
\end{abstract}

Keywords: Chronicles of the Indies; otherness; colonial subject; vision; Antonio de Berrío; Walter Ralegh.

Sumario: 1. Berrío y Ralegh, últimos expedicionarios en busca de El Dorado. 2. La cuestión del otro. 3. Diferencias en la visión del otro en Berrío y Ralegh. 3.1. Visión político-económica. 3.2. Visión cultural y religiosa. 3.3. El europeo como otro. 4. Conclusiones.

Cómo citar: Díaz Ayuga, J.M. (2020) Variaciones europeas en la visión del otro: un estudio contrastivo sobre la otredad en Anotnio de Berrío y Walter Ralegh, en Anales de Literatua Hispanoamericana 49, 295-308.

[D]ende el descubrimiento primero de las Yndias de todas las provinçias dellas se a tenido notiçia de la que llaman El Dorado y por otro nombre la Guayana, [...] que es una de las mayores provinçias más Rica y de más naturales que hasta oy se a descubierto en aquellas partes (Berrío 2010a: 205).

[W]e had adventured [...] to have gone to the great City of Manoa [which the Spanyards call El Dorado], [...]. But it pleased not God so much to favour me at this time [...]. [I]f any else shalbe enabled thereunto, and conquere the same, $[\ldots]$ he shall performe more then ever was done in Mexico by Cortez, or in Peru by Pacaro [...], and whatsoever Prince shall possesse it, that Prince shalbe Lorde of more Gold, and of a more beautifull Empire, and of more Cities and people, then eyther the king of Spayne, or the great Turke (Ralegh 1997: 136). 
Más allá del oro, de la vastedad de las tierras y riquezas sin número, el descubrimiento de América fue, ante todo, el descubrimiento del otro. Una certeza de la que no podía escapar cronista alguno, como podemos comprobar por las citas anteriores, pertenecientes a don Antonio de Berrío, gobernador de Guayana y El Dorado, y a Sir Walter Ralegh, caballero inglés en busca de dicho territorio. En sus descripciones de Guayana, la figura del otro indígena es una constante discursiva, pues, como apunta Rolena Adorno, "el nativo americano -conquistado o indomable- siempre está en el centro de todos los escritos coloniales, aun cuando no se lo mencione" (1988a: 19). Si bien en la historia de la humanidad han sido frecuentes los choques cognitivos entre grupos socioculturalmente diferentes, el encuentro con una otredad tan radical como la americana supuso una perturbación difícilmente asimilable, que amenazaba con destruir las bases geográficas, religiosas, cosmológicas y morales en las que se sustentaba la cultura occidental (Smith 2004). No por nada lo consideraba Todorov "el encuentro más asombroso de nuestra historia" (1987: 58).

Sin embargo, la representación de la otredad se complica en el momento en el que aceptamos que, más allá de la dinámica binaria entre europeos y americanos, existen toda una serie de alteridades internas o próximas (los aztecas para los mayas, o los españoles para los ingleses, por ejemplo), así como diferentes perspectivas dentro del amplio marco enunciativo del llamado sujeto colonizador europeo o del sujeto colonizado americano, que nos permiten observar diferencias en la construcción de la otredad ${ }^{2}$.

En este sentido, las crónicas escritas por Antonio de Berrío y Walter Ralegh en sus respectivas expediciones en busca de El Dorado nos ofrecen un caso paradigmático de estudio, pues ambos realizaron el mismo recorrido por la cuenca del Orinoco y entraron en contacto con las mismas sociedades indígenas en un mismo momento histórico (finales del s. XVI). Ambos testimonios suponen, por lo tanto, una excelente oportunidad para comprobar de qué manera difiere la construcción de la alteridad americana dentro del marco de enunciación del sujeto colonial europeo, así como las razones políticas, económicas o religiosas que subyacen en esa diferencia. Sin embargo, lo interesante de ambas crónicas es que la otredad deja de ser una categoría discursiva exclusiva del indígena y pasa a designar a españoles e ingleses, es decir, para cada uno de estos grupos, el español o el inglés se convierte en "el otro".

A pesar del interés que este tema podría suscitar, no existen investigaciones que comparen el tratamiento de la alteridad en los proyectos coloniales español e inglés. Algo que parece responder a limitaciones geopolíticas y culturales (especialmente lingüísticas) dentro de los estudios coloniales, fruto de herencias coloniales en la distribución del saber (Mignolo 1986; Adorno 1988a). Estas limitaciones nacionalistas y lingüísticas crean fronteras artificiales que, irremediablemente, dejan fuera del corpus de estudio discursos fundamentales para entender las interrelaciones socioculturales que se dieron en zonas como el Caribe, donde el contacto entre españoles, ingleses, franceses y holandeses, entre otros, fue una constante.

Por todo ello, el presente trabajo, a partir de un análisis contrastivo de las crónicas de Berrío y Ralegh, tiene como objetivo establecer posibles diferencias en el tratamiento de la otredad americana, al mismo tiempo que se analiza la configuración de una otredad intraeuropea, lo que puede apuntar a futuras investigaciones en torno a la variación interna en la construcción de la alteridad.

Para dicho análisis nos hemos servido, por una parte, de las numerosas cartas y relaciones con las que Berrío fue informando a la Corona del desarrollo de sus expediciones ${ }^{3}$, así como de ciertos documentos

${ }^{2}$ Tomo la noción de "sujeto colonial" de Bhabha (1986), ateniéndome a la distinción que realiza Adorno (1988b) entre "colonizador" y "colonizado". Por lo que se refiere a la "alteridad u otredad interna", utilizo el concepto tal y como lo define Todorov (1987), en tanto que grupo dentro de la sociedad o cultura de un sujeto (en este caso la europea) a la que este no pertenece. Por su parte, el término de "otredad próxima", acuñado por Smith (2004: 246), alude a las diferencias entre grupos culturalmente semejantes.

${ }^{3}$ Muchas de estas han sido publicadas por Tovar Pinzón (2010): la "Relación o derrotero que hace Antonio de Berrío governador que era de las provincias del Dorado [Santa Fe a 3 de abril de 1585]", la "Carta de Antonio de Berrío al Rey desde las riveras del Casanare [1 de abril de 1587]", la "Jornada de Guayana [1588]", la "Carta de Antonio de Berrio para (su) majestad de la Margarita [26 de octubre de 1591]", la "Carta de Antonio de Berrio [Isla Margarita julio 27 de 1592]", la "Carta a Jherónimo de Velasco [La Margarita 1 de enero de 1593]", la carta titulada "Sobre la importancia de la Guayana [La Trinidad 23 de junio de 1593]", la carta titulada "Que le han ocultado cedulas enviadas por su majestad [Isla de la Margarita 24 de noviembre de 1593]", la "Carta de Antonio de Berrio [Isla de la Trinidad, 2 de Diciembre de 1594]", la carta titulada "Suplica real cedula para que cesen las pretenciones de francisco de vides [1594]", y la "Relación de lo sucedido en el descubrimiento de Guayana y Manoa y otras probincias [1594]". La "Carta de Antonio de Berrío al rey sobre su prisión por Ralegh y el ataque a Cumaná [Margarita 11 julio 1595]", por su parte, solo está publicada en Ojer (1960), mientras que otras, escritas entre 1583 y 1587, no han sido editadas, por lo que las hemos tenido que consultar directamente del Archivo General de Indias: la "Carta a S. M. [Santa Fe 8 de septiembre de 1583]", la "Carta al Visitador del Nuevo Reino, Juan Prieto de Orellana [Río de la Candelaria (Meta) 4 de febrero de 1584]", la "Carta a S. M. [Santa Fe 24 de mayo de 1585]", y otra "Carta a S. M.” de misma fecha y signatura, pero más extensa, y que comienza con "Quarenta años a...". 
relacionados con las mismas ${ }^{4}$, y, por otra, de la última edición publicada de The Discoverie of the Large, Rich and Bewtiful Empyre of Guiana, de Ralegh, editada por Neil L. Whitehead (1997a) 5 .

\section{Berrío y Ralegh, últimos expedicionarios en busca de El Dorado}

A pesar de las diferencias que separan a Berrío y a Ralegh en sus respectivas empresas, ambos comparten un objetivo común: el mítico reino de El Dorado, y se sitúan, dentro de la búsqueda doradista, en una misma etapa, que Ramos Pérez (1973) denomina "neodoradismo", en tanto que supone una revitalización del mito tras el colapso del mismo en la década anterior a $1550^{6}$. A partir de 1549 , llegan al Perú maravillosas noticias acerca de un reino amazónico, Omagua, que de inmediato se sincretiza con el mítico Dorado, reavivando, así, la llama doradista y desplazando su localización al Amazonas. No obstante, el fracaso de las expediciones de Diego Fernández de Serpa (1549) y, en especial, la cruenta travesía de Pedro de Ursúa y Lope de Aguirre (1560-1561), volvieron a desplazar la localización mítica a su espacio original: el país de Meta, situado en los Llanos de Colombia y en la cuenca del Orinoco (Ramos Pérez 1973, Ojer 1966). Si bien las nuevas empresas doradistas resultaron, a su vez, en rotundos fracasos ${ }^{7}$, estas agregarán nuevos datos y leyendas al ya complejo mito de El Dorado: su localización en un gran lago entre montañas, en cuyas orillas se situaría una nueva ciudad mítica, la aurífera Manoa (Ramos Pérez 1973, Ojer 1966).

Es en esta búsqueda de un Dorado complejo y revitalizado en la que se sitúa Antonio de Berrío (15271597), veterano soldado nacido en Segovia que, desde muy joven, había servido a la Corona en Italia, África, Alemania, Flandes y, finalmente, en la sublevación de los moriscos en las Alpujarras (1568). En 1580 se traslada al Nuevo Reino de Granada como heredero de Ximénez de Quesada en la gobernación de El Dorado $^{8}$. A pesar de contar con 53 años, "las grandes notizias que ay de la jornada del Dorado" (Berrío 2010d: 321) bastaron para que Berrío dedicara el resto de su vida y hacienda a la conquista de un Dorado que sitúa ahora en Guayana, por ser el único espacio inexplorado de la región (Ramos Pérez, 1973). A lo largo de doce años llevará a cabo tres expediciones de conquista, en las que entrará en contacto con numerosos pueblos indígenas desde los Llanos hasta la Trinidad, de los que obtendrá reiteradas noticias de "una laguna gandísima" en las sierras de Guayana (Berrío 1585), que inmediatamente identifica con el Dorado de Manoa. Sus jornadas finalizarán con la llegada a la isla de la Margarita, en el Atlántico, donde entra en contacto con ciertas tradiciones sobre El Dorado que le harán reconfigurar su noción del mito; en especial, la idea de El Dorado como refugio construido antes de la Conquista por ciertos incas que emigraron desde el Perú (Ojer 1966) ${ }^{9}$. Con el pretexto de contar con un punto estratégico para nuevas expediciones, funda en 1592 en la isla de la Trinidad la ciudad de San José de Oruña, desde la que envía a su maese de campo, Domingo de Vera e Ibargüen, para que tome posesión de las diversas poblaciones cercanas a El Dorado (Ojer 1960). Si bien su descubrimiento no llega a producirse, Berrío envía a la Corona varias cartas y una relación que tratan de certificar su conquista, así como las "Actas de la toma de posesión". Difícilmente podía imaginar que los documentos serían capturados en alta mar por el capitán George Popham, enviado por Walter Ralegh en 1594 para examinar la costa de Guayana en busca del mítico Dorado (Ramos Pérez 1973, Whitehead 1997a).

El interés de Walter Ralegh (1554-1618) por encontrar dicho territorio surge de su convencimiento en que el futuro de Europa estaría en manos de quien pudiese controlar los recursos auríferos de América. Frente a otros corsarios ingleses, como Francis Drake o John Hawkins, quienes se limitaron al comercio y al saqueo (Ojer, 1966), Ralegh, un personaje polifacético, poeta, soldado, pirata y cortesano, se erige como un caso

${ }^{4}$ A saber: la "Capitulación con Gonzalo Jiménez de Quesada y Antonio de Berrío [18 de noviembre de 1568]", una carta enviada por Berrío a la Real Audiencia, con el título de "El Capitán Antonio de Berrío sobre que se le haga merced en çiertas cossas [15 de octubre de 1582]", las "Actas de las tomas de posesión efectuadas por la expedición española de 1593" y la "Carta de Domingo de Vera sobre la conquista del Dorado [Santiago de León, 17 de agosto de 1593]”. Todas ellas publicadas en Tovar Pinzón (2010).

${ }^{5}$ Para complementar el relato de Ralegh, nos hemos servido, a su vez, de un memorial de servicio y un interrogatorio realizados en Madrid a Francis Sparrey, uno de los soldados que Ralegh dejó en Guayana. Ambos publicados por Ramos Pérez (1973).

${ }^{6}$ Dicho colapso se produce por la acumulación de circunstancias políticas adversas, como la Guerra Civil en el Perú, así como por la muerte o el desinterés de sus principales exponentes, entre otros: Gonzalo Pizarro, Sebastián Benalcázar, Nicolás Federmann, Felipe von Hutten o Gonzalo Ximénez de Quesada (Ramos Pérez 1973).

${ }^{7}$ Entre otras, las del viejo Gonzalo Ximénez de Quesada, en quien habían prendido de nuevo las ilusiones doradistas, así como las de Pedro Maraver de Silva y Diego Fernández de Serpa (Ramos Pérez 1973).

${ }^{8}$ Su mujer, María de Oruña, era sobrina del adelantado (Ojer 1960).

${ }^{9}$ En su "Carta a Jherónimo de Velasco", enviada desde la Margarita en 1593, Berrío apunta por primera vez esta noción de un Dorado incaico en la Guayana: "se dize por cossa cierta q(ue) los reyes yngas de estas probinçias salieron a conquistar el Pirú y después con discordias que ubo entre dos hermanos el uno de miedo del otro se bolvió huyendo a estas provincias" (2010g: 328). 
excepcional dentro del panorama político-económico de la Inglaterra isabelina por su reiterado interés en embarcarse en un proyecto colonial con el que hacer frente a la hegemonía española (Ramos Pérez 1973, Lacey 1973) ${ }^{10}$. Tras su fracaso en 1585 por establecer una colonia en la isla de Roanoke, vuelve su mirada a la Guayana, pues es ahí donde las últimas noticias españolas habían situado el reino de El Dorado (Ramos Pérez, 1973). A través de sus numerosas lecturas Ralegh descubre la importancia del territorio guayanés ${ }^{11}$, pero serán los documentos de Berrío los que le proporcionen una última confirmación acerca de la existencia de oro en la región. En abril de 1595, Ralegh se presenta en la Trinidad y ataca San José de Oruña aprovechándose de la crítica situación en la que se hallaba Berrío por rencillas con las gobernaciones vecinas y el continuo ataque del corso caribe (Ojer 1960). Ralegh contaba, además, con el apoyo de ciertos caciques nativos de la Trinidad que se habían sublevado ante la ocupación española (Ralegh 1997: 132). Toma como rehenes a Berrío y a su lugarteniente, Álvaro Jorge, de quienes obtendrá información esencial sobre el Orinoco y Guayana. Su expedición, sin embargo, que no logra superar los intentos anteriores de Berrío y Domingo de Vera, se encuentra con problemas semejantes: la ausencia de grandes cantidades de oro y la hostilidad de ciertas poblaciones indígenas. En un último intento desesperado, Ralegh trata de saquear las poblaciones españolas de la Margarita y Cumaná con el fín de obtener las riquezas que no pudo hallar en Guayana, pero es derrotado en ambos casos, debiendo canjear a Berrío y a Jorge por algunos de sus soldados en Cumaná (Ojer 1966). Al llegar a Inglaterra, publica de inmediato el Discoverie (Londres, 1596), como forma de convertir su fracaso colonial en un éxito discursivo, sustituyendo la falta de riquezas materiales con información sobre las naciones nativas del Orinoco que, según Ralegh, asegurarían un éxito colonial a largo plazo $^{12}$.

\section{La cuestión del otro}

Como ya apuntábamos en la introducción, esa otredad radical que es el indígena americano se convierte en un tema omnipresente al que es imposible no dirigirse, y que atraviesa, de forma constante, los discursos de Berrío y Ralegh.

En la construcción de esa otredad, son fundamentales, de acuerdo con Adorno (1988b), los conceptos de "focalización" y "visión" desarrollados por la profesora Mieke Bal (1985). Por "visión" entiende Bal un punto de vista concreto, condicionado por la posición del sujeto enunciador respecto a un ente "otro", así como por el conocimiento previo y la actitud psicológica que se tiene hacia él; la focalización, por su parte, sería la relación entre la visión, el agente que ve y lo que es visto. Al ser una "visión, creada y comunicada por un agente determinado", esta se destaca de "la ilusión de ser neutral, universal o inocente" (Adorno 1988b: 57). De esta forma, el sujeto colonial (colonizador, en nuestro caso), no se define por ser quien es en tanto "agente que ve", sino por la perspectiva adoptada en la construcción del "otro". No importa si el que habla es o no europeo, ya que lo que lo define es la visión que presenta: una visión que se inscribe dentro de los valores de la Europa imperial y de su proyecto colonial (Adorno 1988b) ${ }^{13}$. La relación que se establece con la otredad americana a través de esta visión europeizante y colonial no puede ser más que asimétrica y jerárquica. Es por ello que normalmente la construcción de la alteridad se basa en un modelo interpretativo de oposiciones binarias, donde cada término representa una posición extrema, sin grados intermedios, y donde uno (en este caso el indígena) es siempre considerado inferior y, por tanto, relativamente negativo (Adorno 1988b, Pratt 2010) ${ }^{14}$. Al basarse en distinciones jerárquicas, la otredad se convierte en un término de interrelación (normalmente de carácter económico y político) más que de separación entre el "yo" y el "otro", pues, de acuerdo con Smith (2004), la otredad es siempre un rasgo contrastivo donde el "otro" se

${ }^{10}$ La intención de Ralegh no es la de llevar a cabo “journeys of picorie” (1997: 121-122), ya que entendía que la piratería por sí misma no era suficiente para hacer mella en la ingente cantidad de recursos que los españoles controlaban en el interior.

${ }^{11}$ El propio Ralegh cita algunas de sus principales fuentes textuales, como Pedro de Cieza, Francisco López de Gómara o André Thevet. Asimismo, cabe destacar su lectura del Discourse of Western Planting de Richard Hakluyt (1584), sobre la fecundidad en potencia del territorio, y la Historia de los Incas, de Pedro Sarmiento de Gamboa (1572) (Whitehead 1997a).

${ }^{12}$ Hemos de pensar que su texto fue, al mismo tiempo, una forma de recuperar el favor de la reina virgen, quien, tras descubrir en 1592 el matrimonio secreto entre Ralegh y una de sus damas de la Corte, Elizabeth Throckmorton, mandó encarcelar a ambos por varios meses. Ralegh, en consecuencia, dejó de contar con el apoyo de la soberana (Lacey 1973, Montrose 1993, Whitehead 1997a).

${ }^{13}$ Jitrik, por su parte, emplea el término "aparato interpretativo" (1992: 77) para aludir a lo que aquí denominamos como "visión".

${ }^{14}$ En la base de este modelo se halla un principio común a la mayor parte del pensamiento griego, según el cual "there exists in all complex forms a duality in which one element naturally dominates the other" (Pagden 1982: 42). Esta noción influirá en muchos de los pensadores europeos que escriban sobre la alteridad indígena, entre ellos Francisco de Vitoria y Juan Ginés de Sepúlveda (Adorno 1988b). 
define por su diferencia con respecto a un "yo". Esta diferencia puede establecerse a través de tres modelos básicos de oposiciones. En primer lugar, el "otro" se representa metonímicamente en términos de presencia o ausencia de uno o más rasgos culturales o físicos: en América, la ausencia de ropa, armas de fuego o escritura, por ejemplo, fueron utilizados para definir al "otro", al mismo tiempo que el "yo" quedaba descrito en términos de presencia. En segundo lugar, el "otro" puede definirse topográficamente en términos de centro y periferia: el "yo" es aquel que habita dentro de los límites (de la sociedad, de la civilización, de lo humano), mientras que el "otro", más allá de sus fronteras, suele identificarse con lo desconocido y lo monstruoso. Por último, el "otro" puede representarse lingüística o intelectualmente en términos de ininteligibilidad: es el bárbaro (en el sentido aristotélico del término), aquel que carece de habla y de razón, al que el "yo" no es capaz de entender (Smith 2004).

Por lo general, a la hora de establecer la diferencia con la alteridad americana, el colonizador optó por modelos de oposiciones binarias previamente existentes en la mentalidad europea. Así, por ejemplo, la aplicación del modelo de cruzadas a las guerras de conquista equiparaba al indígena con el musulmán en tanto que infiel y enemigo del cristianismo (Cesareo 1995: 443), mientras que la consideración, común en numerosos textos doctrinales, de los indígenas como niños o mujeres, que, por su naturaleza emocional e irracional, debían someterse a la autoridad del hombre adulto, yuxtaponía "los discursos de dominación y jerarquización domésticas e imperiales" (Adorno 1988b: 62). La caracterización del indígena como rudo, pobre o falto de cultura, coincidía, por otra parte, con la representación que las clases altas europeas realizaban de las clases populares (Mason 1990). De esta forma, al definir la relación entre europeos e indígenas a través de modelos interpretativos preexistentes, se le negaba su reconocimiento como una entidad realmente "otra", diferente pero igual en cuanto al reconocimiento de su existencia aparte del "yo"15. El discurso colonial acerca de la alteridad americana no surge, por lo tanto, de un deseo por conocer al otro, sino, principalmente, como una forma de diferenciar jerárquicamente al "yo" colonizador del "otro" colonizado, justificando la dominación colonial con esquemas de dominio presentes en la Europa precolombina. Es a través de este discurso, como aparato de poder, que se conforman las diferencias y discriminaciones: se establece quién es superior y quién inferior y por qué. (Bhabha 1986, Adorno 1988b).

Dentro de esa visión europeizante y colonial, basada en oposiciones binarias de diferenciación jerárquica, podemos encontrar "profundas diferencias entre culturas nacionales y creencias religiosas de los diversos viajeros europeos, diferencias que constituían de modo decisivo tanto sus percepciones como sus representaciones [de la otredad]" (Greenblatt 2008: 37). Por ello, en las páginas que siguen, analizaremos las diferencias existentes dentro de la visión colonial que Berrío y Ralegh claramente comparten, de acuerdo con las características político-económicas, culturales y religiosas de sus respectivos proyectos de conquista. Ello nos permitirá entender sus diferentes representaciones de la alteridad indígena, así como la configuración de españoles e ingleses como un "otro" próximo.

\section{Diferencias en la visión del otro en Berrío y Ralegh}

\subsection{Visión político-económica ${ }^{16}$}

En la relación político-económica con la otredad nativa, una de las diferencias más significativas la encontramos en la configuración del mundo indígena del Orinoco y Guayana como un todo prácticamente homogéneo en Berrío, frente a la caracterización de dicho espacio como un heterogéneo mapa de sociedades diversas en Ralegh. En los testimonios del primero, el indígena es siempre referido con los genéricos "indio" o "natural", individuando únicamente las figuras de los caciques Morequito y Carapana, por la relevancia geográfica de sus territorios, cercanos al supuesto Dorado. De esta forma, la otredad se presenta solo como

\footnotetext{
${ }^{15}$ Como señalan Greenblatt (1990, 1991), Todorov (1987) y Smith (2004), el gran problema en la conceptualización de la otredad se halla en la incapacidad para considerar al "otro" como diferente y semejante al mismo tiempo, sin que su consideración como ser humano completo, igual al europeo, le lleve a ser considerado una entidad idéntica, asimilable al "yo", ni que la diferencia se traduzca en una relación jerárquica de superioridad e inferioridad, perfección e imperfección.

${ }^{16}$ A pesar de que, por motivos de utilidad metodológica, hayamos establecido una división entre elementos político-económicos y elementos culturales y religiosos, dentro del proyecto colonial estos aspectos se hallan en íntima interrelación. La dominación política y económica tendía a justificarse a partir de la falta de cultura o religión por parte de un determinado grupo (Pagden, 1982), mientras que la resistencia del indígena a la colonización podía entenderse como muestra de salvajismo o incluso de intervención diabólica, lo que justificaba un "necesario" proceso de aculturación civilizadora y evangélica (Mason 1990).
} 
una sucesión innumerable de "gentes" y "poblaçiones", como una masa informe de la que no se realizan distinciones de tipo geopolítico, cultural o incluso físico. Es, sin embargo, ese carácter de masa innumerable el que interesa a Berrío. Desde la primera descripción que realiza de los indígenas, destaca su gran número, pues ello se traduce en mano de obra para la producción de riquezas y la fundación de ciudades: "hay indios en tanta cantidad que se pueden poblar dos ciudades" (Berrío 1584) ${ }^{17}$. El número de indígenas llega a ser un tema casi obsesivo en sus testimonios, una forma de demostrar al rey la riqueza de esas provincias ante la falta de enormes cantidades de oro:

[P]regunteles si había tanta gente [en la cordillera] como en los llanos. Reíanse de mí diciendo que en la cordillera había muchos lugares y que en cada uno de ellos había mucha más que en todos los llanos. Le prometo a Vuestra Majestad que vi y hablé en ellos a más de veinte mil y donde se ven veinte hay más de ciento (Berrío 1585).

Esta representación del indígena como masa indiferenciada llega hasta el extremo de la cosificación ${ }^{18}$, en tanto que, en numerosas ocasiones, Berrío enumera a la población nativa sin solución de continuidad entre otros bienes materiales ${ }^{19}$. Así, nos dice Berrío de la Trinidad: “[e]s tierra muy abundante de yuca y maís y caña du(1)ze [...] pero lo mejor que ay en ella es la sercanía a la tierra firme, los muchos naturales y mucha cantidad de Piraguas" (Berrío 2010d: 326).

La única distinción que Berrío establece es entre indios pacíficos y belicosos, identificando a estos últimos con los caribes. Más que una distinción etnográfica, la denominación de "caribes" (así como la de "arahuacos") se utilizaba con frecuencia para dividir a los indígenas según su respuesta a la ocupación española: aquellos que aceptaban su presencia solían ser llamados "arahuacos" (pacíficos), mientras que los que se defendían con las armas eran denominados "caribes" (belicosos) (Whitehead 1997a, Mason 1990). En ambos casos, la designación estaba destinada a justificar su sometimiento a la Corona, pues su carácter pacífico implicaba que serían fácilmente subyugables, mientras que el énfasis en la resistencia violenta justificaba el uso de la fuerza ${ }^{20}$. Asimismo, con intenciones políticas, Berrío llega a invertir los signos "pacífico"/"belicoso", aun cuando designa a una misma población. En su llegada a Trinidad, por ejemplo, trata de demostrar al rey el fácil poblamiento de la isla, por lo que los nativos son descritos como "gente muy doméstica" (Berrío 2010d: 324). Sin embargo, cuando sus derechos de posesión sobre ella quedan en entredicho por las alegaciones del gobernador Vides, Berrío intenta demostrar el gasto económico y humano empleado en la pacificación de los indígenas, con lo que estos son ahora "más de siete mill yndios de guerra [...] la mayor parte dellos no paçificos" (Berrío 2010f: 351-352).

Frente a lo anterior, asombra la cantidad de información geopolítica que Ralegh despliega en su Discoverie acerca de las mismas poblaciones. Si bien ya contaba con numerosos testimonios de la zona, incluyendo los de Berrío, lo cierto es que la mayor parte de la información la obtiene de sus observaciones de la población nativa, en especial a través de sus intercambios con el cacique Topiawari, tío de Morequito. Ralegh logra dibujar un completo mapa político-social de la realidad indígena del Orinoco y Guayana, registrando el nombre de los diferentes caciques y poblaciones, y reflejando la jerarquía del bajo Orinoco (Whitehead 1997a). A diferencia de Berrío, quien es ya gobernador de esos territorios y es consciente de la hegemonía hispana sobre los mismos (Ojer 1966), Ralegh necesita el apoyo logístico y militar de los indígenas para hacer frente a los españoles. Parte, por lo tanto, del convencimiento de que, para poder llevar a cabo la conquista, necesita obtener la mayor información posible sobre ellos con el fin de establecer

${ }^{17}$ El objetivo de crear ciudades en la gobernación guayanesa será una constante en Berrío, quien, en una de sus últimas cartas escribe: "suplico a $\mathrm{b}$ (uestra) $\mathrm{m}$ (agesta)d [...] me faboresca [...] para que antes que me muera dexe pobladas algunas çiudades en aquellas rricas provinçias y mi cuerpo enterrado en ellas pues tanto travajo le cuesta" (Berrío 2010g: 342).

${ }^{18}$ Jitrik alude con el término "cosificación de lo «otro»" (1992: 74) a este tipo de configuración del indígena como material o mercancía.

${ }^{19}$ Hemos de pensar que en el s. XVI los repartimientos y encomiendas seguían siendo uno de los premios más esperados de las expediciones de conquista. Las tierras inmensamente pobladas eran, por tanto, fuente de una enorme riqueza (Tovar 2010, Del Vas Mingo 1985). El propio Berrío promete al gobernador de Venezuela, Diego Osorio, "quatro legoas de tierra pobladas de yndios" a cambio de su apoyo (2010f: 349).

${ }^{20}$ Esta justificación cobra especial relevancia tras las Ordenanzas de 1573, que trataron de sustituir los asentamientos como penetración violenta por un contacto pacífico con los indígenas. Para ello, se sustituye el término "conquista" por el de "pacificación", si bien en la práctica la diferencia era puramente formal (Del Vas Mingo 1985). 
alianzas. Lo paradójico, sin embargo, es que son dos españoles, Cortés y Pizarro, quienes le servirán de principales modelos en este aspecto $^{21}$ :

I came to understand the situations, the rivers, the kingdoms [...], and of all the kings of Provinces and captains of townes and villages, how they stood in tearms of peace or war [...], without which there can be neither entrance nor conquest [...]: For by the dissension betweene Guascar and Atabalipa, Paçaro conquered Peru, and by the hatred that the Traxcallians bare to Mutezuma, Cortez was victorious over Mexico (Ralegh 1997: 149).

Lo primero que hace al llegar a Trinidad es obtener información acerca de las poblaciones nativas de la isla. En su conversación con Topiawari se centra en conocer el estado sociopolítico de Guayana, "what sort of common wealth it was, how governed, of what strength and pollicy", así como, por supuesto, su relación con "the Spaniards" (Ralegh 1997: 172-173). Sin embargo, Ralegh no se limita a ofrecer información sobre los diversos grupos nativos, sino que, a diferencia de la masa indiferenciada que veíamos en Berrío, individualiza la figura del indígena a través de una serie de personajes principales, a los que dota de dignidad e incluso de voz. De Carapana, por ejemplo, nos ofrece Ralegh una breve biografía (1997: 150), mientras que a Topiawari lo presenta, incluso, como un individuo capaz de tener "inward feeling", una profunda tristeza por "the losse of his conntrey and liberty" (173). No obstante, debemos entender esta dignificación del indígena en Ralegh como un artificio retórico con el que destacar dos elementos en su discurso: la crueldad de los españoles, quienes no arremeten contra una entidad genérica ("indios" o "naturales"), sino contra entes individuales, muchos de ellos grandes señores ${ }^{22}$; y su enorme capacidad como etnógrafo, así como su habilidad para interactuar y aliarse con las naciones nativas.

Por otra parte, el sometimiento de las sociedad nativas a "the tyrannie of the Spaniards" (Ralegh, 1997: 172), las convertía inmediatamente en aliadas naturales de los ingleses, quienes, según Ralegh, sufrían en Europa el mismo yugo del poder hispano (127). Si la representación del indígena pacífico u hostil estaba destinada en Berrío a justificar el sometimiento a las huestes españolas, en Ralegh, su construcción como pueblo sometido, "all at peace, [...] each one holding the Spaniard for a common enimie" (1997: 174), legitima, a su vez, su sometimiento a la Corona inglesa, solo que esta vez como forma de salvación ante la brutalidad hispana. La imagen de los ingleses como salvadores de los nativos se reitera, así, a lo largo del Discoverie: "I made him know [...] that the Queenes pleasure was, I should undertake the voyage for their defence, and to deliver them from the tyrannie of the Spaniards" (172-173). Como forma de ulterior legitimación, Ralegh inscribe la figura del inglés como salvador en la propia cosmología e historia nativas. Para ello, altera la leyenda de la emigración incaica (que debió de obtener de Gamboa, Cieza o Berrío), achacándola a la invasión española del Perú (136), y complementa esta supuesta enemistad entre españoles e incas de Guayana con un supuesto mito peruano según el cual "from Inglatierra those Ingas shoulde be againe in time to come restored, and delivered from the servitude of the said Conquerors" (199). De esta forma, Ralegh invierte los términos del deseo colonial: su incursión no responde al afán de explotación económica de Guayana, como ocurriría en el caso español, sino a la petición misma de los indígenas, quienes, ateniéndose a su propia historia y mitología, anhelan ser liberados y, por ende, conquistados por los ingleses: "All [...] seeme to desire nothing more then her Majesties protection, and the returne of the Engilsh nation" $(122)^{23}$.

En ambos casos, por tanto, nos encontramos ante una oposición binaria entre "dominadores" y "dominados", y ambas, como veremos, responden a una visión estereotípica del sujeto colonizador en la que se reproducen los valores del ideal caballeresco masculino. Para Adorno (1988b), el máximo representante de esos valores sería Juan Ginés de Sepúlveda, quien, en su Demócrates segundo o de las justas causas de la guerra contra los indios (1547), justifica la dominación de los europeos sobre los indígenas por una superioridad natural basada en oposiciones jerárquicas con las que se legitimaba la dominación de otras alteridades en Europa: mujeres, niños, brujas, musulmanes, locos, etc. (Mason 1990). De acuerdo con Sepúlveda, estas alteridades compartían con el indígena su incapacidad para gobernarse, su crueldad, su

\footnotetext{
${ }^{21}$ Cortés hace explícita en su memorial de 1537 a Carlos V esta estrategia: "[antes de conquistar una región, hay que] saber si es poblada, y de qué gente, e qué ley o rito tienen, e de qué viven, e lo que hay en la tierra" (cit. en Todorov 1987: 3299).

${ }^{22}$ Con este fin, se presentan, por ejemplo, los nombres de los caciques torturados por los españoles en San José de Oruña (1997: 134).

${ }^{23}$ Sabemos, sin embargo, que la enemistad de los indígenas con los españoles no era tal (Ojer 1966). Asimismo, el testimonio de Francis Sparrey nos ofrece casos de hostilidad nativa contra los ingleses que Ralegh, astutamente, omite: "entró el rrio adentro 130 leguas, y en este paraxe acudió mucho número de yndios a defender la subida del rio" (Sparrey 1973: 672).
} 
carácter violento y emocional, su apetito feroz (normalmente relacionado con la antropofagia), su lujuria, y su entrega al exceso en general, en oposición al caballero cristiano europeo, quien, quedaba, así, definido como un ser moderado, entregado a la paz y a la razón, capaz de gobernarse a sí mismo y, por ende, a su "otro" femenino/indígena (Todorov 1987, Adorno, 1988b).

Berrío, por su parte, se erige como un claro exponente de la visión masculina caballeresca, pues los nativos son descritos como "haraganes" (Berrío, 1585) o bien como seres violentos que no atienden a la paz que les ofrece: "[E]n este lugar hicieron los indios una junta de gente, vinieron a pelear conmigo, requeriles con la paz y no queriéndola fue menester pelear" (1585). A esta representación responde, a su vez, la identificación de los indígenas belicosos con caribes caníbales ${ }^{24}$. En la segunda expedición se nos narra cómo los nativos, tras haber muerto a cuatro españoles, tomaron a uno de ellos "para comerselo por ser carives" (Berrío 2010c: 282). Lo interesante, sin embargo, es que este episodio, referido en la "Jornada de Guayana [1588]" por otros doce testigos, no es considerado por ocho de ellos como un caso de canibalismo. En Berrío, la supuesta antropofagia sirve, más bien, a modo de construcción discursiva que añade a la representación del otro rasgos inhumanos, de crueldad extrema, en los que impera el desorden y el ruido por encima de la moderación y la palabra: “eran muchísimos y venían con fututos y gritería y dando a entender que venían a pelear” (Berrío 2010c: 283). Con ello, el conquistador segoviano no solo busca justificar el uso de la violencia con los nativos, sino definirse, por oposición, como un sujeto pacífico y moderado, que únicamente emplea las armas cuando su vida depende de ello. Es esa superioridad "natural" la que legitima, en última instancia, el sometimiento de los nativos a su gobierno ${ }^{25}$.

La visión que ofrece Ralegh del indígena, es, por su parte, completamente opuesta. Incluso en el caso extremo de los caníbales ("Canibals"), a quienes considera "of [...] barbarous nature", no llega a deshumanizarlos asociando sus prácticas con la antropofagia, sino que los relaciona con la venta de esclavos, algo que, en realidad, resulta ser obra de los españoles, quienes "make great profit, [...], they sell them againe at Marguerita in the west Indies" (1997: 179), con lo que la naturaleza bárbara del caníbal surge como consecuencia de la barbarie ulterior de la esclavitud española. Por lo general, la representación del indígena en Ralegh supone una inversión de los términos "femeninos" con los que tradicionalmente se le designaba, aplicándole rasgos positivos pertenecientes al paradigma de lo "masculino"26. De esta forma, valora a sus potenciales aliados como activos de confianza en la guerra contra el español. En su descripción de los indios "Tivitivas" (o guaraúnos), por ejemplo, Ralegh destaca su virilidad, asociando a ella elementos como la valentía, la bondad, o la capacidad de elaborar un discurso reflexivo: "These Tivitivas are a verie goodlie people and verie valiant, and have the most manlie speech and most deliberate that ever I heard of what nation soever" (158-159). Los caciques Carapana y Topiawari, por otra parte, aparecen caracterizados como sujetos juiciosos e inteligentes, y de gran experiencia. La edad hiperbólica que Ralegh les atribuye a ambos (cien años), sirve asimismo para destacar dichos atributos: "Carapana, a man very wise, subtill, and of great experience, being little lesse than 100. yeeres old" (150); "[Topiawari] is a man of great understanding and pollicie: he is above 100. yeeres old" (152). Sin embargo, esta visión "masculina" del indígena se problematiza en el momento en el que descubrimos la duplicidad estratégica del Discoverie (Montrose, 1993). Pues si, por una parte, el texto de Ralegh impulsa a la Corona inglesa a intervenir en favor de estos nativos a los que tan positivamente valora, este, al mismo tiempo, invita sistemáticamente a la explotación de las ricas tierras de Guayana, con lo que su actitud de alianza y amistad no sería más que un engaño para seguir contando con el necesario apoyo de los indígenas ${ }^{27}$ :

[A]s yet our desier of gold, or our purpose of invasion is not known unto those of the Empire: \& it is likely that if her majestie undertake the enterprize, they will rather submit themselves to her obedience then to the Spanyards, of whose cruelty both themselves \& the borderers have alreadie tasted (Ralegh 1997: 184).

\footnotetext{
${ }^{24}$ Tanto si las prácticas caníbales, de las que en ningún momento Berrío y sus hombres son testigos, son reales o supuestas, estas son una parte fundamental en la evaluación europea del indígena como ser entregado al exceso (al apetito extremo) (Pagden 1982).

${ }^{25}$ La moderación con la que Berrío se identifica llega hasta tal punto que, tras la destrucción de San José de Oruña por parte de Ralegh y los indígenas de Trinidad, asegura al rey que "[castigará] a los indios con alguna moderación” (Berrío 1960: 202).

${ }^{26} \mathrm{Al}$ emplear las designaciones de "masculino" y "femenino", aludo a los extremos de la oposición binaria a la que antes nos referíamos (Montrose 1993, Adorno 1988b).

${ }^{27}$ De esta forma, Ralegh parece estar solicitando de sus lectores lo que Greenblatt denomina un "olvido ideológico" (1991: 157) de su proyecto de imposición colonial, para que el discurso de valoración y liberación de los indígenas siga teniendo sentido.
} 
Es en este discurso de dominación colonial donde la retórica de sometimiento de lo indígena como "femenino" vuelve a funcionar. Como bien señala Montrose (1993), se produce una sustitución metonímica de las valoradas sociedades masculinas por la tierra como ente feminizado (Guayana), como cuerpo virgen a la espera todavía ("yet") de la consumación colonial: "Guiana is a Countrey that hath yet her Maydenhead, [...] never conquered or possesed by any Christian Prince" (Ralegh 1997: 196). De esa forma, integrando a las sociedades de hombres amerindios en el "otro" femenino de la tierra, la subyugación de los indígenas por parte de los ingleses queda autorizada por el dominio "natural" del hombre hacia la mujer (Montrose, 1993), emparentando, así, los discursos y objetivos colonialistas de Ralegh y Berrío.

\subsection{Visión cultural y religiosa}

Las diferentes construcciones político-económicas del otro amerindio, como sujeto sometido en Berrío y como potencial aliado en Ralegh ${ }^{28}$, llevan, a su vez, a diferentes actitudes hacia su cultura.

Uno de los elementos que más destaca Berrío en su representación del "otro" es su desnudez: "atravesé [...] por muchas provincias pobladas de indios, aunque desnudos" (Berrío 1585); "todos gente desnuda e pobres, porque no tienen metales ni mas que un poco de yuca" (Berrío 2010b: 240). La desnudez en Berrío implica, al mismo tiempo, "desnudez" económica y cultural: se produce un vaciamiento de la categoría del "otro", quien se construye como "signo vacío" (Greenblatt 2008: 133), en oposición al signo pleno del español, culturalmente "vestido" (Jitrik 1992) ${ }^{29}$. Hay, por tanto, un absoluto desinterés por el otro en tanto que sujeto cultural: no se describen sus ritos o costumbres, aun cuando el input recibido es propicio para ello. En su segunda expedición, por ejemplo, al encontrar un enorme bohío "con mucha cantidad de guesos de hombres" (Berrío 2010b: 241), Berrío continúa su relato sin plantear hipótesis alguna que explique la presencia de huesos o la función del bohío en cuestión ${ }^{30}$. En su visión principalmente político-económica de la otredad, la información que incluye sobre la realidad socio-cultural indígena se halla supeditada, por una parte, al establecimiento de ciudades en su gobernación, como ocurre en la enumeración de recursos alimenticios, "yuca e pesquería y venados", que le sirven para sustentar "mi gente sin neçesidad" (Berrío 2010b: 240); y, por otra, a su búsqueda de El Dorado: Berrío solo registra aquellos marcas significativas que sean indicio de una mayor civilización y desarrollo técnico-económico, como la presencia de "caminos muy seguidos y poblasones mui buenas" (2010c: 281), o la existencia de comercio entre los indios de los Llanos y los de la sierra (Berrío 1585), que pueden guiarle a la rica sociedad de los incas de Guayana, "gente vestida y [...] muy rrica" (2010e: 357).

Por su parte, la imagen cultural que Ralegh nos ofrece está lejos de la "desnudez" señalada por Berrío, hasta el punto de omitir la propia desnudez física, para evitar toda significación de pobreza o ausencia. El Discoverie puede leerse como una suerte de relato proto-etnográfico de la vida del Orinoco (Whitehead 1997a), donde se detalla, por ejemplo, información sobre las viviendas y ritos funerarios de los tivitivas (Ralegh 1997: 158-159), sobre los ritos matrimoniales de los orenoqueponi (193), sobre el comercio de oro proveniente de Guayana, o sobre su uso decorativo en las élites nativas (145). Tal abundancia de datos etnográficos no solo responde a la ya mencionada estrategia cortesiana por conocer al potencial aliado, sino que supone una respuesta narrativa al "fracaso" económico de su empresa, una sustitución del oro prometido por sustanciosa información acerca de las naciones a conquistar ${ }^{31}$.

Estas diferentes construcciones de la cultura "otra" van a llevar aparejadas estrategias diferentes de relación cultural. En el caso de Berrío, su consideración de la cultura indígena como tabula rasa, en línea con la mayoría de descripciones europeas de los indígenas del Caribe (Whatley 1986, Greenblatt 1990), invita a prácticas de aculturación, muy en relación con el carácter de misión evangélica que para la Corona española tenía la Conquista. En sus capitulaciones, se obliga a Berrío a llevar consigo "ocho clerigos o

\footnotetext{
${ }^{28} \mathrm{Al}$ menos en un primer nivel discursivo, como hemos visto.

${ }^{29}$ En la visión de Berrío, su desnudez les priva, además, de características distintivas que permitan diferenciarlos dentro de la masa del genérico "indígena" o "natural".

${ }^{30}$ Sorprende, asimismo, que en sus numerosas descripciones de la desembocadura del Orinoco, no llegue a mencionar las curiosas edificaciones palafíticas de los guaraúnos o tivitivas que Ralegh sí recoge (1997: 158).

${ }^{31}$ Como él mismo justifica ante sus inversores: "I have hitherto onely returned promises, and nowe for answeare of both your adventures, I have sent you a bundle of papers [...] for that it is reason, that wastful factors, when they have consumed such stockes as they had in trust, doe yeeld some cullor for the same in their account" (1997: 120).
} 
religiosos para instruir los naturales" (“Capitulación”, 2010: 150), y en ningún momento olvidará la importancia de dicha misión, pues la utilizará como argumento para demostrar la necesidad de su jornada: "para que un servicio tan grande se haga a Dios redimiendo tantas ánimas como se pueden redimir, suplico [...] a esta Real Audiencia tomen a su cargo el ayudarme a levantar la gente" (Berrío 1585).

Ralegh, por su parte, se aleja del proyecto aculturador subyacente en la empresa de Berrío, y se sitúa a posta en lo que Pratt denomina una "zona de contacto", entendida esta como un espacio social de encuentro entre culturas, por lo general en relaciones asimétricas de dominación, pero donde se producen con frecuencia movimientos transculturadores (2010: 31). En dicho espacio relacional, Ralegh privilegia la semejanza sobre la diferencia, la simbiosis y la asimilación por encima del aislamiento o la imposición cultural, activando así un proceso mimético con el que buscar activamente convergencias culturales, e incorporando elementos de una cultura en la otra (Whitehead 1997b). Podemos hablar de dos movimientos culturales en dicho proceso. Por una parte, Ralegh asimila elementos de la cultura nativa a la realidad inglesa, como sucede, por ejemplo, en la mencionada valoración de las virtudes indígenas en términos del ideal caballeresco europeo, o en la proyección de la campiña inglesa en los valles del Orinoco: "the valley of Amariocapana [...], with divers copses scattered heere and there by the rivers side, and all as full of deare, as any forrest or parke in England" (Ralegh 1997: 186-187) ${ }^{32}$. En otras ocasiones, sin embargo, es la cultura anglosajona la queda asimilada a la realidad nativa. Este es el caso de la inclusión de la liberadora "Inglatierra" (199) en el supuesto universo mitológico de los incas, así como la integración de la reina Elizabeth I en la jerarquía política del Orinoco como "Ezrabeta Cassipuna Aquerewana, which is as much as Elizabeth, the great princesse" (134). A esta estrategia asimiladora responde, a su vez, el especial "Requerimiento" que Ralegh lleva a cabo, emulación del español, pero que su intérprete traduce, ajustando la realidad política anglosajona a la nativa, y convirtiendo, así, a los capitanes de la reina en "Casiqui" (134). Estos dos movimientos miméticos entre ambas culturas están dirigidos en el Discoverie a producir una alianza natural entre ingleses e indígenas, con el fin de legitimar políticamente la usurpación por parte de los ingleses de los territorios españoles. Estas estrategias de legitimación están presentes en otros escritores noreuropeos y protestantes, quienes desacreditaban los derechos de posesión de españoles y portugueses por estar basados, únicamente, en las concesiones de la Iglesia. Consideraban necesario cualquier tipo de asentamiento material o, en este caso, una estrecha relación, tributaria o de cualquier tipo, con la población nativa (Montrose 1993, Whitehead 1997a).

Esta relación pragmática con la cultura "otra", así como el desinterés por la aculturación, están relacionados, a su vez, con la ausencia de un afán evangélico en los países protestantes (Greenblatt 1990). La doctrina calvinista, por ejemplo, problematizó la posibilidad de llevar a cabo la actividad misionera, pues, al enfatizar la inmutabilidad de las escrituras y privilegiar una fuente religiosa pura, criticaba toda adaptación de la religión a la realidad nativa.

\subsection{El europeo como otro}

Las diferencias entre ambos sujetos coloniales, sin embargo, no se limitan a su visión de la otredad americana. La presencia de españoles e ingleses en una misma "zona de contacto" propició procesos de diferenciación con esa otredad ontológicamente próxima.

Si bien Berrío ofrece en una carta al rey información acerca de su captura por Ralegh, o "Guatarral" (Berrío 1960: 200), como solían denominarlo los españoles, su representación del inglés es limitada. De él destaca su crueldad extrema y su falta de palabra, rasgos para Berrío inconcebibles incluso en un corsario inglés:

[E]nviaba grandes juramentos y prometiendo grandes seguridades. [...] Y no embargante esto, [...] hizo una de las mayores traiciones y crueldades que se ha oído jamás en el mundo, porque mandó atar a Don Rodrigo de la Hoz, mi sobrino, y a los otros soldados, [...] y atados los mandó matar a puñaladas (201).

\footnotetext{
${ }^{32}$ Si bien, como señala Jitrik (1992), el uso de la metáfora o la analogía se convierte en algo esencial para presentar la realidad americana a un lector desconocedor de la misma, no se nos escapa que, en el fondo, se trata de una posesión simbólica del territorio.
} 
Sin embargo, lo interesante en su construcción de la otredad anglosajona es que, al final de su carta, atribuirá esta inesperable crueldad y falta de palabra a su carácter de "herejes" (202), cuya derrota a manos de los católicos españoles es fruto de la intervención divina: "fue Dios el que hizo aquese castigo" (202). De esta forma, Berrío, para establecer la diferencia con la alteridad, acude al modelo predominante en el Caribe, donde la lucha entre colonos españoles y piratas ingleses y franceses (mayoritariamente hugonotes), adquirió un carácter de lucha religiosa entre católicos y protestantes (Ojer 1966).

Mucho más compleja y central es, sin embargo, la construcción de la alteridad española en el Discoverie de Ralegh. El español acaba convirtiéndose en "una idea fija que le domina y obsesiona" (Ramos Pérez 1973: 480). En primer lugar, Ralegh, consciente de las numerosas expediciones españolas a El Dorado, necesita demostrar la importancia de su empresa por encima de todas ellas. Es por ello que, a lo largo del Discoverie, Ralegh se define, por oposición a los españoles, como un explorador inteligente, hábil en sus relaciones diplomáticas y etnográficas con los indígenas, a los que ha logrado convertir en "her Majesties vassals" (122) y de quienes obtiene información totalmente desconocida por los españoles ${ }^{33}$. Es esta superioridad diplomática y logística la que legitima los derechos de posesión ingleses sobre los españoles, pues se presentan como aliados naturales de los nativos y como los verdaderos artífices del "discoverie" guayanés:

Berreo $[\ldots]$ who $[\ldots]$ hath spent 300000 . ducates in the same, and yet never could enter so far into the land as my selfe with that poore troupe or rather a handfull of men, being in all about 100 . gentlemen $[. .$.$] neither could any of the forepassed undertakers, nor Berreo himself discover the$ country (144).

Los españoles, por su parte, se definirían por su total desinterés e incomprensión de la realidad nativa: "[Berrío] knew not the names of any of these [rivers], [...] for he had no meanes to discourse with the inhabitants [...]: neither was he curious in these things, being utterlie unlearned, \& not knowing the east from the west” (149); así como por su falta de aliados indígenas (200-201) ${ }^{34}$.

No obstante, la principal diferencia sobre la que Ralegh construye a ese "otro" próximo en el Discoverie se basa en una oposición fundamental entre moderación y exceso, continencia e incontinencia; distinción que descansa en los ya mencionados valores de la ideología caballeresca masculina, pero en la que Ralegh sustituye la oposición "europeo" / "indígena" -"hombre" / "mujer", por la de "inglés" / "español"-. La decisión de los ingleses de no abusar de su propia posición dominante sobre los indios, su capacidad de superponer la razón al deseo, de autocontrolarse ante las atrayentes riquezas de Guayana, es lo que les permite distinguirse de los incontinentes españoles, quienes se entregan a la codicia, la lujuria, la crueldad y demás excesos, al mismo tiempo que los legitima como mejores gobernantes de los nativos (Montrose, 1993). Pero no solo a una visión caballeresca masculina responde dicha oposición. Ralegh, a quien se había acusado de no ser capaz de controlar sus impulsos, por su matrimonio con una de las damas de la Corte, buscaba con su Discoverie redimirse ante la reina virgen, adoptando la retórica de castidad y demora que la propia soberana empleaba como estrategia política. Hasta tal punto llega su interés redentor, que convierte su viaje a Guayana en un peregrinaje simbólico ("a paineful pilgrimage"), con el que expiar sus pecados ante la reina, recuperando su perdida "moderation of excesse" (Ralegh 1997: 121).

Es por ello que los españoles aparecen representados como extremadamente crueles, torturando indígenas en Trinidad (133) o masacrando a los súbditos de Morequito en Arromaia (152), así como seres con una incontrolable sed de oro (184). Todo ello engrandece moralmente la figura del Ralegh peregrino, quien "could have laid hands and ransomed many of the kings \& and Cassiqui of the Country [...]: But [...] have chosen rather to beare the burthen of poverty" (121-124). Un episodio en concreto muestra claramente esta oposición entre moderación inglesa y exceso español. En su viaje por el Orinoco, encuentran a un grupo de indios arahuacos que temen a los ingleses por considerarlos caníbales, pues tal es la noticia que han recibido de los españoles. Ralegh y los suyos desmienten el engaño español ofreciéndoles comida, con lo que no solo

\footnotetext{
${ }^{33}$ Sus afirmaciones llegan al extremo de asegurar que ha obtenido de los nativos el antídoto a un veneno (el "curare"), que no solo desconocían los españoles, sino que "every one of these Indians know it not, no not one among thousands, [they] conceale it, and onely teach it but from the father to the sonne" (172).

${ }^{34} \mathrm{Si}$ bien Ralegh es bastante perspicaz en cuanto al desinterés de Berrío por la realidad cultural nativa, el resto de afirmaciones carecían de fundamento: su "descubrimiento" no era tal cuando desde principios del XVI los españoles trajinaban el Orinoco (Ojer, 1966); tampoco es cierta la falta de intérpretes, pues, desde la primera jornada, alude Berrío a su "lengua" (Berrío, 1585); y Carapana, quien se muestra esquivo y ambiguo con Ralegh, fue uno de los principales aliados de Berrío.
} 
invierten el gesto antropofágico, sino que ponen de relieve la diferente naturaleza de españoles e ingleses (Montrose 1993):

$[\mathrm{W}]$ hen $[\ldots]$ we gave them meate, and to everie one some thing or other, which was rare and strange to them, they began to conceive the deceit and purpose of the Spaniards, who indeed (as they confessed) tooke from them both their wives, and daughters daily, and used them for the satisfying of their owne lusts (165).

De esta forma, son los españoles quienes se lanzan al extremo del "consumo" indígena para satisfacer sus excesos. Los ingleses, por su parte, no solo logran controlar su libido, sino que invierten los gestos al ofrecer en lugar de tomar:

I protest before the majestie of the living God, that I neither know nor beleeve, that any of our companie $[. .$.$] by violence or otherwise, ever knew any of their women, and yet we saw many$ hundreds, [...] very yoong, and excellently favored which came among us without deceit, starke naked (165). ${ }^{35}$

Sin embargo, esta oposición jerárquica entre ingleses y españoles, moderación y exceso, en un principio tajante, comienza a volverse problemática por dos motivos. En primer lugar, utilizando esos mismos términos, Ralegh establece diferencias de clase dentro de los propios ingleses: "But I confesse it was a very impatient worke to keepe the meaner sort from spoile and stealing" (165). Como ya hemos apuntado, era común que en la Europa de la época las clases altas considerasen a los sectores populares como una otredad interna caracterizada por rasgos "femeninos" (Montrose 1993). Así, la incapacidad de estas clases para gobernarse a sí mismas justificaba una estructuración jerárquica de la sociedad, en los mismos términos en los que se legitimaba la superioridad de los ingleses sobre los españoles. Ahora bien, esta valoración de las clases altas lleva a Ralegh, incluso, a valorar positivamente a Berrío por su pertenencia a la misma: "This Berreo is a gent. well descended, and had long served the Spanish king [...], very valiant and liberall, and a Gent. of grat assurednes, and of a great heart: I used him according to his estate and worth in all things I could" (135). Con ello, la diferencia inicial entre españoles e ingleses se diluye en favor de una especie de solidaridad transnacional de clase en la que Ralegh y Berrío se equipararían (Montrose 1993). En segundo lugar, dicha oposición binaria solo funciona en uno de los dos niveles discursivos del Discoverie: la empresa anglosajona como liberación de las naciones indígenas. Es ahí donde la moderación legitima a los ingleses como gobernantes más justos. Sin embargo, en un nivel ulterior, la moderación se transforma en demora estratégica de la explotación colonial (Montrose 1993), un engaño con el que hacer creer a los indígenas que existe una diferencia entre el conquistador español y el inglés, que su sometimiento a los segundos los liberará del yugo del colonialismo despiadado:

[I]t woulde have been in mine opinion an utter overthrowe to the enterprize, if the same [to sack and spoil the Indians] should be hereafter by her Majestie attempted: for then (whereas now they have heard we were enemies to the Spaniards and were sent by her Majestie to relieve them) they would as good cheape have joyned with the Spanyards at our returne, as to have yeelded unto us, when they had proved that we came both for one errant, and that both sought but to sacke and spoyle them, but as yet our desier of gold, or our purpose of invasion is not known unto those of the Empire: \& it is likely that $[\ldots]$ they will rather submit themselves to her obedience then to the Spanyards (Ralegh 1997: 184-185). ${ }^{36}$

La diferencia que tan insistentemente había tratado de establecer con el español como "otro" se neutraliza por la identificación de ambos como un mismo sujeto colonizador europeo, cuyo objetivo común ("to sacke and spoyle them") diluye sus pretendidas distancias en una misma relación de poder y explotación

\footnotetext{
${ }^{35}$ Por supuesto, el énfasis en el cuerpo desnudo como objeto de deseo, así como su asimilación a patrones de belleza europea en otros pasajes (153, 168 ), aumentan el valor de la hazaña continente de los ingleses.

${ }^{36} \mathrm{La}$ estrategia de demorar su empresa de conquista para no descubrir sus objetivos reales a los indígenas y para demostrar a la reina su habilidad de contención, en el fondo no es más que un nuevo intento de justificar su rotundo fracaso económico (Montrose 1993).
} 
imperialista con la alteridad americana: "we came both for one errant". Los españoles se convierten, así, en modelos masculinos a los que emular y superar. Sus actos de penetración colonial, inscritos en una retórica caballeresca de dominación sexual, son vistos con admiración y deseo (Montrose, 1993). "Charles the fifte, who had the Maydenhead of Peru" y "the affaires of the Spanish king now living [Felipe II]" (127) pasan de ser crueles figuras de la otredad a anheladas formas de la identidad europea.

Como apunta Smith (2004), son las distinciones con la otredad más próxima las que se vuelven más problemáticas. La otredad radical del indígena es considerada meramente como un "otro"; el español, por su parte, aunque lingüística, cultural e históricamente ajeno, forma parte de un mismo sistema económico, social y político europeo que lo acerca irremediablemente. Es ante este "proximate other" que surge la teoría del otro: no de la necesidad de situar lo diferente, sino para establecer nuestra propia identidad dentro del contexto de lo semejante, pues, como bien señala Adorno, "la alteridad es una creación que permite establecer y fijar las fronteras de la identidad" (Adorno 1988b: 67).

\section{Conclusiones}

El análisis contrastivo de los testimonios de Ralegh y Berrío nos ha permitido establecer diferencias en la visión que el sujeto colonizador europeo tiene de la alteridad americana, dependiendo de las condiciones en las que se desarrollaron los proyectos coloniales anglosajón e hispánico. Estas distinciones en la consideración política del indígena, en la relación cultural que se estableció con el mismo o en cómo se lo situó dentro de marcos discursivos previos a la Conquista, convierten la noción de sujeto colonizador europeo propuesta por Bhabha (1986) y Adorno (1988b) en un concepto, quizás, demasiado amplio. No obstante, como demuestra el relato de Ralegh, el choque de las diversas naciones europeas con la otredad radical americana y su intento común por explotarlo en tanto que fuente de riqueza colonial, puso en funcionamiento nuevos mecanismos de identidad con los que dichas naciones trataron de diferenciarse unas de otras, legitimando al mismo tiempo su relación con la otredad indígena por encima de las demás. Todas, sin embargo, "came [...] for one errant". Es en su deseo común por permanecer en el marco de la dominación colonial donde ese juego de otredades próximas se vuelve problemático, y donde la noción de sujeto colonizador europeo vuelve a cobrar significado.

\section{Referencias bibliográficas}

Adorno, Rolena (1988a), "Nuevas perspectivas en los estudios literarios coloniales hispanoamericanos", Revista de Crítica Literaria Latinoamericana, 28 (1988a): 11-28.

Adorno, Rolena (1988b), "El sujeto colonial y la construcción cultural de la alteridad", Revista de Crítica Literaria Latinoamericana, 28 (1988): 55-68.

BAL, Mieke. Narratology: Introduction to the Theory of Narrative. Christine van Boheemen (trad.). Toronto: University of Toronto, 1985.

Berrío, Antonio, "Carta al Visitador del Nuevo Reino, Juan Prieto de Orellana [Río de la Candelaria (Meta) 4 de febrero de 1584]", Archivo General de Indias, PATRONATO, 27, R.35.

Berrío, Antonio, "Carta a S. M. [Santa Fe 24 de mayo de 1585] («Quarenta años a...»)", Archivo General de Indias, PATRONATO, 254, N.2, G.2, R.2.

Berrío, Antonio (1960), "Carta de Antonio de Berrío al rey sobre su prisión por Ralegh y el ataque a Cumaná [Margarita 11 julio 1595]", en Pablo Ojer. Don Antonio de Berrío: gobernador del Dorado. Caracas: Universidad Católica Andrés Bello, pp. 199-204.

Berrío, Antonio (2010a), "El Capitán Antonio de Berrío sobre que se le haga merced en çiertas cossas [15 de octubre de 1582]", en Hermes Tovar Pinzón. Relaciones y visitas a los Andes: siglo XVI. Tomo V. Región de los Llanos. Bogotá: Instituto Colombiano de Cultura Hispánica, pp. 203-234.

Berrío, Antonio (2010b), "Relación o derrotero que hace Antonio de Berrío governador que era de las provincias del Dorado [Santa Fe a 3 de abril de 1585]", en Hermes Tovar Pinzón. Relaciones y visitas a los Andes: siglo XVI. Tomo V. Región de los Llanos. Bogotá: Instituto Colombiano de Cultura Hispánica, pp. 235-270.

Berrío, Antonio (2010c), "Jornada de Guayana [1588]", en Hermes Tovar Pinzón. Relaciones y visitas a los Andes: siglo XVI. Tomo V. Región de los Llanos. Bogotá: Instituto Colombiano de Cultura Hispánica, pp. 277-306.

Berrío, Antonio, (2010d), "Carta a Jherónimo de Velasco [La Margarita 1 de enero de 1593]”, en Hermes Tovar Pinzón. Relaciones y visitas a los Andes: siglo XVI. Tomo V. Región de los Llanos. Bogotá: Instituto Colombiano de Cultura Hispánica, pp. 321-331.

Berrío, Antonio (2010e), "Sobre la importancia de la Guayana [La Trinidad 23 de junio de 1593]", en Hermes Tovar Pinzón. Relaciones y visitas a los Andes: siglo XVI. Tomo V. Región de los Llanos. Bogotá: Instituto Colombiano de Cultura Hispánica, pp. 353-359. 
Berrío, Antonio (2010f), “Que le han ocultado cedulas enviadas por su majestad [Isla de la Margarita 24 de noviembre de 1593]”, en Hermes Tovar Pinzón. Relaciones y visitas a los Andes: siglo XVI. Tomo V. Región de los Llanos. Bogotá: Instituto Colombiano de Cultura Hispánica, pp. 349-353.

Berrío, Antonio (2010g), “Carta de Antonio de Berrio [Isla de la Trinidad, 2 de Diciembre de 1594]”, en Hermes Tovar Pinzón. Relaciones y visitas a los Andes: siglo XVI. Tomo V. Región de los Llanos. Bogotá: Instituto Colombiano de Cultura Hispánica, pp. 332-343.

Bhabha, Homi K. (1986), "The other question: difference, discrimination and the discourse of colonialism", en Francis Barker, Peter Hulme, Margaret Iversen y Diane Loxley (eds.). Literature, Politics, and Theory. Londres: Methuen, pp. 148-172.

"Capitulación con Gonzalo Jiménez de Quesada y Antonio de Berrío [18 de noviembre de 1568]" (2010), en Hermes Tovar Pinzón. Relaciones y visitas a los Andes: siglo XVI. Tomo V. Región de los Llanos. Bogotá: Instituto Colombiano de Cultura Hispánica, pp. 145-172.

Cesareo, Mario (1995), “Jerónimo Mendieta: razón barroca, delirio institucional”, Revista iberoamericana, vol. 61, 172-173 (1995): 441-460.

Del Vas Mingo, María Milagros (1985), "Las Ordenanzas de 1573, sus antecedentes y consecuencias”, Quinto Centenario 8 (1985): 83-101.

Greenblatt, Stephen (1990). Learning to curse. Londres: Routledge.

Greenblatt, Stephen (2008). Maravillosas Posesiones: El Asombro Ante El Nuevo Mundo. Barcelona: Marbot.

Jitrik, Noé (1992). Historia de una mirada. El signo de la cruz en las escrituras de Colón. Buenos Aires: Ediciones de la Flor.

Lacey, Robert (1973). Sir Walter Ralegh. London: Weidenfeld \& Nicolson.

Mason, Peter (1990). Deconstructing America: Representations of the Other. Londres: Routledge.

Mignolo, Walter (1986), "La lengua, la letra, el territorio (o la crisis de los estudios literarios coloniales)", Dispositio Vol. 11, No. 28/29 (1986): 137-160.

Montrose, Louis (1993), "The work of gender in the discourse of discovery", en Stephen Greenblatt (ed.). New World Encounters. Berkeley: University of California Press, 1993: 177-217.

Ojer, Pablo (1960). Don Antonio de Berrío: gobernador del Dorado. Caracas: Universidad Católica Andrés Bello.

Ojer, Pablo (1966). La Formación del Oriente venezolano. Caracas: Universidad Católica Andrés Bello.

Pagden, Anthony (1982). The Fall of Natural Man: The American Indian and the Origins of Comparative Ethnology. Cambridge: Cambridge University Press.

Pratt, Mary Louise (2010). Ojos Imperiales: Literatura De Viajes Y Transculturación. México: Fondo de Cultura Económica.

Primera bula Inter Caetera (2010)[1493]. Argentina: Biblioteca Virtual Universal, pp. 1-4. Disponible en: www.biblioteca.org.ar/libros/158131.pdf

Ralegh, Walter (1997). The Discoverie of the large, rich, and bewtiful empyre of Guiana. Manchester: Manchester University Press.

Ramos Pérez, Demetrio (1973). El Mito del Dorado: su génesis y proceso: con el Discovery de Walter Raleigh (traducción de Betty Moore) y otros papeles doradistas. Caracas: Academia Nacional de la Historia.

Smith, John (2004). Relating Religion. Essays in the study of Religion. Chicago y Londres: Chicago University Press.

Sparrey, Francis (1973), "Memorial del servicio que haze el capitan Francisco Sparri, yngles", en Demetrio Ramos Pérez. El Mito del Dorado: su génesis y proceso: con el Discovery de Walter Raleigh (traducción de Betty Moore) y otros papeles doradistas. Caracas: Academia Nacional de la Historia, pp. 671-677.

Todorov, Tzvetan (1987). La conquista de América. El problema del otro. (Versión Kindle). México: Siglo XXI.

Tovar Pinzón, Hermes (2010). Relaciones y visitas a los Andes: siglo XVI. Tomo V. Región de los Llanos. Bogotá: Instituto Colombiano de Cultura Hispánica.

Whatley, Janet (1986), "Savage Hierarchies: French Catholic Observers of the New World", The Sixteenth Century Journal 17 (1986): 319-330.

Whitehead, Neil L. (1997a), "Introduction", en The Discoverie of the large, rich, and bewtiful empyre of Guiana. Manchester: Manchester University Press, pp. 1-116.

Whitehead, Neil L. (1997b), "Monstrosity and marvel: symbolic convergence and mimetic elaboration in trans-cultural representation: an anthropological reading of Ralegh's Discoverie...”, en Studies in Travel Writing 1:1 (1997b): 7295. 